\title{
Improving Teachers' Quality of Teaching Reading Through Professional Development
}

\author{
Ying Wang \\ Mississippi Valley State University, Mississippi, USA \\ Duane Shuttlesworth \\ Delta State University, Mississippi, USA. \\ Sherill France-Morris \\ Mississippi Valley State University, Mississippi, USA
}

\begin{abstract}
The Mississippi Delta is a largely rural, agricultural, and poverty-stricken region with underfunded schools. Reading levels in these schools fall below state and national standards. Providing teachers of reading with evidence-based skills and knowledge is one way to improve Mississippi Delta students' reading performance. The No Child Left Behind (NCLB) Summer Reading Institute conducted in June 2015 with two follow-up sessions in the academic years of 2015 and 2016 offered a rich professional development (PD) opportunity to 20 local reading teachers from Grades 6-12 in the Mississippi Delta. The institute focused on enhancing the knowledge and skills of teachers of reading by nurturing their own reading habits. Multiple evaluations of teacher performance took place including pre- and post- test, a field trip, an overall program evaluation, and focus group discussions. Follow-up focus group discussions also occurred. Collectively, the results from both qualitative and quantitative analysis based on these evaluations suggested that the institute was successful in providing teachers with useful knowledge, skills, and strategies needed to teach reading and language arts more effectively to their students in Grades 6-12. Improved teaching of reading promotes higher academic performance and greater success of the students in the Mississippi Delta.
\end{abstract}

Keywords: reading instruction, professional development, academic performance

\section{Introduction}

Imagine the life of a person who cannot read. Imagine a 6th grade student's academic learning experiences without reading skills. Imagine what being a poor reader can lead to-dropping out of school, unemployment, poverty, and more. Never has before the importance of reading skills and the quality of teaching reading received such an emphasis in the United States. Widely held beliefs make the teacher the key to students' academic performance and success. As a result, the professional development (PD) of teachers has become the most promising means of improving the quality of teaching in a variety of content areas including reading. The

Ying Wang, Dr., professor of Literacy Education, Department of Teacher Education, Mississippi Valley State University.

Duane Shuttlesworth, Dr., professor of Psychology, Department of Psychology, Division of Counselor Education and Psychology, Delta State University.

Sherill France-Morris, Dr., assistant professor of Criminal Justice, Department of Criminal Justice, Mississippi Valley State University. 
need for PD is most pressing for teachers who teach in high-poverty schools in poor areas because of statewide accountability and across-the-board implementation of assessment standards for students.

The Mississippi Delta is one of the poorest areas in the nation where approximately $97 \%$ of the African Americans in this region reside in the central 10 counties of the Mississippi Delta (U.S. Census of Bureau, 2016), and an area serviced academically by Mississippi Valley State University (MVSU). Poverty, inadequate school funding, and lack of teaching resources have a potentially dramatic effect on student learning. The reading performance of students in the Mississippi Delta is considerably lower than the statewide performance level. In school years of 2014-2015, for example, students across the State of Mississippi participated in the Partnership for Assessment of Readiness for College and Careers (PARCC) testing program in English II (The Mississippi PARRC Assessment, 2015). The test results ranged from accountability Level 1 to Level 5 indicating minimal, partial, adequate, strong, and distinguished understanding, respectively. The average percentage performance level for the Mississippi Delta for each level (from Level 1 to Level 5) were 28.15\%, $24.8 \%, 23.4 \%, 21.9 \%$, and $1.75 \%$. By contrast, the statewide average performance levels (from Levels 1 to Level 5) were $11.6 \%, 15.8 \%, 23.3 \%, 36.6 \%$, and $12.8 \%$. According to the PARCC (2015) results, students scoring at Levels 4 or 5 were meeting or exceeding expectations. Over $76.35 \%$ of the students from the Mississippi Delta did not meet expectations.

In summer 2015, Mississippi Valley State University received the No Child Left Behind (NCLB) Title II Part A Improve Teacher Quality Program federal funds to provide the Mississippi Delta reading teachers with opportunities to receive PD training in reading to enhance teaching quality to improve their students' reading performance and produce an overall improvement in academic outcomes. In this paper, we discuss the NCLB Summer Reading Institute that offered PD training to improve the quality of reading instruction for a group of 20 Mississippi Delta reading teachers. Firstly, we describe the reading program. Then, we explore literature on the importance of PD for improving teachers' quality. Next, we share the method of the study and results. Finally, we discuss the effect of the program on the Mississippi Delta teachers' reading instruction.

\section{The Institute}

The MVSU NCLB Summer Reading Institute offered 20 days of PD training in June 2015 to 20 local teachers, the majority of who were Grades 6-12 reading and language arts teachers from local schools around MVSU. Two follow-up sessions occurred in October 2015 and February 2016. Over the course of the program, participants engaged in 22 sessions designed to improve their knowledge and skill in the teaching of reading, and their implementation of the Common Core State Standards (CCSS). The MVSU NCLB Summer Reading Institute is an incentive-based PD program providing a $\$ 100$ per day per participant stipend, an average of about $\$ 400$ worth of books, and instructional materials for each participant. Teacher participants also earned six Continuing Education Units upon the completion of the program.

Examples of the books that the teacher participants received include Hey! Listen to This by Jim Trelease; Once Upon a Time When We Were Colored by Clifton L. Taulbert; Mercedes and the Chocolate Pilot by Margot Theis Raven; Classic Fairy Tales published by the Greenwich Workshop Press; John Muir: America's First Environmentalist by Kathryn Lasky; Children of the Great Depression by Russell Freedman; Memoirs of a Goldfish by Devin Scillian; The Pirate Captain's Daughter by Eve Bunting; Research-Based Methods of Reading Instruction by Sharon Vaughn and Sylvia Linan-Thompson; Moon over Manifest by Clare Vanderpool; A Sick Day for Amos McGee, illustrated by Erin E. Stead, written by Philip C. Stead; Alexander and the 
Terrible, Horrible, No Good, Very Bad Day by Judith Viorst; The One and Only Ivan by Katherine Applegate; and a selection of two books from Junie B. Jones' series written by Barbara Park.

The institute started each day with a 30-minute Read Aloud session. Each teacher chose one story from the book Hey! Listen to This by Jim Trelease to read aloud. The participants could team with other participants to produce a play or they could rewrite the story into a Reader Theater script to play at the session.

Content-oriented sessions covered the following major topics: discussion of the state standards; Bloom's Taxonomy: developing students' critical thinking skills; Schema Theory; differentiated instruction using the Madeline Hunter Method; reading assessment; African American children's literature: making books come alive; African American adolescent literacy: bridging the gaps between the classics and literacy intervention, increasing rigorous content and literacy, and using technology to make learning more engaging and interesting. A Delta Cultural Field Trip provided teachers with an opportunity to understand their students' backgrounds and cultural history. The final products of the institute were lesson plans and thematic units the teachers could use in their teaching of reading.

The overall goal of the institute was to equip teachers with the knowledge and skills necessary to teach reading, one of the core subjects for Grades 6-12. Did the institute achieve its intended goals? We asked the three questions:

1. Did the institute successfully equip teachers to teach reading and language arts to students in Grades 6-12?

2. Did the institute enhance participants' knowledge and skills required to increase student achievement in reading?

3. What changes could we make to improve the institute?

\section{Literature Review}

Poverty and the lack of resources affect the learning of students in the Mississippi Delta. The Mississippi PARCC assessment results reflect these conditions, indicating that in the school years of 2014-2015, only 23.65\% students of the school districts participating in the institute met or exceeded the expectations. Numerous studies discuss the connections between the quality of teaching and student achievement. Therefore, PD is a means to provide knowledge, skills, and resources to improve the quality of teaching to facilitate student success. Skourdoumbis (2014), Skourdoumbis and Gale (2013), Henry et al. (2014), Gordon, Kane, and Staiger (2006) studied teacher effectiveness and student achievement, finding that there were differences in the amount and kinds of learning that different teachers help produce in their classes. They suggested that students taught by proficient teachers showed greater progress than students with ineffective teachers did.

PD is a well-documented means of improving teacher quality. In today's knowledge-based society, PD for teachers is a significant way to sustain and improve the quality of teaching. Janssen, Kreijins, Bastiaens, Stijnen, and Vermeulen (2012) examined the effects of PD on a group of Dutch teachers who received guidance on teaching through their professional development programs. They found that guided teachers were more capable of identifying their strengths and formulating learning goals than unguided teachers were. In addition, guided teachers were more capable of developing rigorous plans of action for instruction.

Podhajski, Mather, Nathan, and Sammons (2009) studied the effects of PD on scientifically based reading instruction. Four teachers and 33 students participated in 35 hours of training on phonemic awareness, phonics and fluency. The results suggested, "Teachers can improve their knowledge concerning explicit reading 
instruction and that this new knowledge may contribute to student growth in reading" (p. 403). Wang (2013) reported that PD improved the quality of teaching reading for teachers in the central Mississippi Delta. Through the four-week intensive training with two follow-up sessions, the participating teachers showed improvements in performance on measures of content knowledge and teaching skills.

While the CCSS goals and objectives are straightforward, there is greater flexibility and freedom in determining how to reach the goals and objectives in English Language Arts (ELA). According to the CCSS, teachers are "free to provide students with whatever tools and knowledge their professional judgment and experience identify as most helpful for meeting the goals set out in the standards" (Common Core State Standards Initiative, 2012, p. 4). This presents a new challenge to teachers and administrators-what instructional practices and resources would be most helpful for meeting these goals? The purpose of the NCLB Summer Institute is to help teachers in the Mississippi Delta answer this question.

\section{Methodology}

\section{Demographic Information}

Participants were 14 females and six males. Ninety-five percent were African American. Participants ranged in age from 24 to 58 years with an average age of 41.5 years. The average years of teaching experience for this group was 10.4 years, with $35 \%$ serving between 11 and 15 years, and $20 \%$ serving for over 16 years in the teaching profession. Forty-five percent of the participants held Class AA, Master's degree level licenses, while $40 \%$ had A-level, Bachelor's degree level licenses. The remaining $15 \%$ of the participants held emergency certificates, temporary teaching certificates granted to individuals who do not meet the ordinary certification criteria.

\section{Research Design}

The evaluation plan used multiple measures, multiple data sources, and both quantitative and qualitative data to answer each of the central questions. This approach was to improve the validity of the evaluation results and ensured that the evaluation was not reliant on a single data source. Participants completed pre- and posttest evaluations assessing the critical content areas covered during the institute. Other measures were a field trip evaluation, program evaluation, participant focus groups discussion, and follow-up focus groups discussion.

\section{Data Analysis}

We used both quantitative and qualitative techniques to gather data to assess and evaluate the effectiveness of the NCLB Summer Reading Institute. The quantitative data augmented to the findings from the focus groups' discussions and the qualitative data analysis. The evaluation survey instruments had both open- and closedended questions designed to elicit responses specific to the objectives of the program.

The qualitative data gathered in focus group discussions and responses to the open-ended questions on the survey instruments captured: (a) responses in real space and time in the context of face-to-face interactions; and (b) strategically "focusing" interview prompts based on themes generated in these by face-to-face interactions and considered particularly significant to the researchers (Kimberelis \& Dimitriadis, 2005, p. 899). Information often surfaced through focus groups that might not otherwise occur with other data-gathering techniques. According to Madriz (2000), the focus group is "a collectivistic rather than an individualistic research method that focuses on the multivocality of participants' attitudes, experiences, and beliefs" (p. 836), generating rich data through direct interaction with teacher participants in combination with other data-gathering techniques." 


\section{Results}

Twenty teachers attended and took part in the four-week activity in June 2015 and two follow-up sessions, one in the Fall Semester of 2015 and another in the Spring Semester of 2016.

\section{Pre-Test and Post-Test}

The pre-test occurred on the first day of the institute and the post-test took place on the 19th day at the institute. The assessment instrument consisted of 60 questions, 50 multiple-choice questions, and 10 short answer questions in the areas of knowledge, skills, application of the standards, and theory in reading and reading instruction.

A paired sample $t$-test compared the pre-test and post-test results. As shown in Table 1, on average, participating in the institute increased participants' knowledge and skills of the subject matter (post-test results had a $M=68.35, S E=2.08)$ compared to the pre-test results obtained at the beginning of the institute $(M=$ 27.35, $S E=1.93)$. The difference between the means was statistically significant $(t=20.314, d f=19, p \leq$ $0.001)$. The post-test mean was 41 points higher than the pre-test mean suggesting a significant change resulted from the teachers' participation in the institute. The disparity between the pre-test and post-test standard deviation was less than 1.0 indicating that the rates of learning among the participants were almost the same.

Table 1

Paired Sampls Descriptive Statistics

\begin{tabular}{llllllll}
\hline & $N$ & Range & Minimum & Maximum & Mean & $s$ & $S E$ \\
\hline Pre-test & 20 & 34 & 10 & 44 & 27.35 & 8.63 & 1.93 \\
Post-test & 20 & 30 & 50 & 80 & 68.35 & 9.3 & 2.08 \\
\hline \multicolumn{2}{l}{ Paired samples test } & & & & & \\
\hline \multicolumn{2}{r}{ Mean } & $S$ & $S E$ & 95th CI & $t$ & $d f$ & Sig. (2-tailed) \\
\hline Post-pre test & 41 & 9.03 & 2.02 & $36.78-45.22$ & 20.314 & 19 & $P \leq 0.001$ \\
\hline
\end{tabular}

Table 2

Representative Reasons for Satisfaction with Field Trip

1. The trip took me to places I had not visited before and broadened my scope of where I might want to take my students to;

2. The trip exposed me to a lot of things I had never heard before;

3. I was very satisfied, because I learned a lot of valuable information about the Delta, the environment, and the people that helped make the Delta what it is today;

4. I was satisfied with it, because it actually put a face on all the stories that I read to my students. They would enjoy a field trip like this;

5. I was totally satisfied with the field trip mainly because of the history that lies along the route taken;

6. Overall, the trip was very informative, because we visited places I would normally pass by.

\section{Field Trip}

The Mississippi Delta Culture Field Trip occurred on Day 10 at the institute. The group visited the Emmitt Till court trial site in Sumner, Mississippi, the Mental Health Rehabilitation Region I Center in Clarksdale, Mississippi, and the Clarksdale Blues Museum. The trip evaluation instrument consisted of two questions that gathered information from the participants about their feelings toward the trip and its relevance to their understanding of their culture, the students they teach, and how the experience gained would affect their teaching. Question 1 asked the participants if they were satisfied with the field trip. Eighteen of the 20 participants went on the trip and all indicated satisfaction with the experience. Their reasons for this rating follow in Table 2. 
Question 2 asked the participants to state how their experiences on this trip would affect their teaching. Table 3 presents selected responses to this question.

Table 3

How My Trip Experience Will Affect My Teaching?

1. I have a renewed sense of the history of this area;

2. It will allow me to provide my students with experiences that they can relate to in their lives;

3. The trip has broadened my thinking about the events and trial of Emmet Till;

4. It will affect my teaching in that I can share my experiences with my students, and possibly plan a trip for them along the same trail;

5. I will incorporate Mississippi's history and events in my classes;

6. I will integrate what I learned from the trip in my social studies lesson plan and instruction;

7. This will help me teach my students about the past;

8. This trip helped me as a teacher to learn of important things we have around our own community. It also gave me more

knowledge about our history;

9. It will allow me the opportunity to relate first hand information to my students;

10. I really would like to take my students on a field trip like the one we had;

11. I now have a better understanding of the Delta and its culture;

12. I am eager to help our students learn about the historical sites and resources that are here in Mississippi;

13. This field trip is very educational for me. I can only imagine how valuable it would be if students were exposed to this type of field trip;

14. I truly appreciate the Delta trip. There is a wealth of information that most Deltians should know about their history.

\section{Overall Program Evaluation}

The program evaluation survey administered at the end of the program assessed the participants' overall impression and satisfaction with the institute. Question 1 asked the participants to give the institute an overall rating on a scale of 1 to 5 with " $1=$ Poor" and " $5=$ Excellent." Ninety-five percent $(n=19)$ of the participants rated the institute excellent and $5 \%(n=1)$ rated the institute good.

When asked what program activities they liked most, the participants identified the following:

1. The Field Trip-This was the most cited activity. Participants indicated that they experienced parts of Mississippi they did not know existed and that they gained new insights into the history of Mississippi, learned about the culture, and received valuable information they could share with their students. As one participant wrote, it put "a picture to all the stories that I have read;

2. Presentations from the State Department of Education provided valuable information on the state's English Language Arts (ELA) assessments and strategies they could employ in their classroom;

3. Developing Thematic Units-Participants stated that they gained knowledge about the subject area, and they saw the importance and relevance of using this teaching strategy. Some participants also indicated that this approach was new to them;

4. Differentiated Instruction (DI) - One participant explained, "Every year we are told to use DI, but nobody took the time to explain how to implement it;"

5. Reading Assessment-Participants expressed amazement at the results of using the Readability Graph by Fry to identify the grade level of reading materials. The book, The One and Only Ivan, has 319 pages, yet, it is a third-grade reading level book. The book, Children of the Great Depression, has 118 pages with lots of photos in it is an eighth-grade level book. As one of the participants pointed out, "There is no correlation between the reading level and pages of a book;"

6. Group activities/hands-on work-As indicated by the participants, working in groups with their colleagues allowed for sharing what they knew on related topics; they could make mistakes and receive a positive critique and feedback on how to make corrections; 
7. The demonstration of the seven teaching strategies, and how to increase rigor;

8. Technology sessions - How to infuse technology in their teaching;

9. Resources received - The participants all expressed gratitude for the books provided by the institute and felt that they would be very useful in supporting an enhancement of their instruction in the coming school year.

When participants rated the efficiency of management of the Summer Institute on a four point Likert Scale with "Very Good = 4," "Good = 3," "Fair = 2," and "1 = Poor," 95\% $(n=19)$ felt that it was very good and 5\% $(n=1)$ indicated it was good.

\section{Focus Group Discussions}

In addition to gathering information on the participants' satisfaction with the institute, the focus group discussions afforded in-depth information on perceptions, insights, attitudes, experiences of the learning environment, their motivation and enthusiasm to use the material provided, and their suggestions for improvement. Two focus group discussion sessions occurred at the end of the program, with 10 participants in the first group and nine participants in the second group.

\section{What Participants Intend to Change in their Classrooms because of this Training?}

When we asked the focus group what they intend to change or do differently in their classrooms, they responded with the following (see Table 4):

\section{Table 4}

What Participants Intend to Change in Their Classrooms Because of This Training?

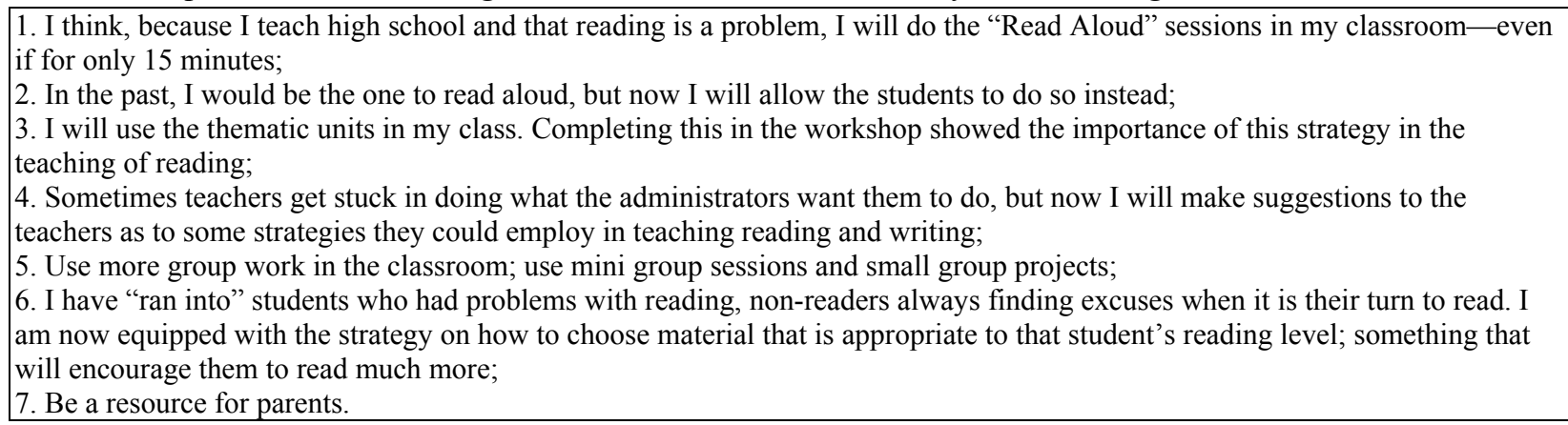

\section{Two Follow-Up Session Focus Group Discussions}

The two follow-up session focus group discussions provided further and in-depth information on the participants' work and activities since the conclusion of the Summer Institute. These discussions occurred at the end of each follow-up session and lasted about one hour. We asked two questions:

1. What have you done differently in your classrooms since the Institute?

2. How did the information you received from the institute affect your students' learning, if any?

In response to the first question, teacher participants reported they employed the strategies they learned from the presenters. Frequent strategies mentioned included the use of the grouping method, improved teaching vocabulary, enhanced comprehension strategies, use of square organizers, thematic units, random calling names on sticks to get all students to participate in the class, graphic organizers, incorporating real world experiences/real life events that affect children into their lessons, using C-Coding to teach science, think-pair-share strategy, making more use of the children literature in teaching, argumentative writing, and identifying reading level before assigning materials to students to read. One teacher told us: 
This institute has added great value and quality to my instruction. It has provided me with an extended wealth of strategies, knowledge, and best practice that has enhanced my instruction. I now have a variety of strategies that I model for my students and use in my classroom that has enhanced their reading, writing, comprehension, vocabulary, and overall learning experiences. They (my students) have experienced academic growth this year that I credited in part to my newfound knowledge because of this institute.

Another teacher participant recounted an event with her new assistant principal:

My assistant principal was excited when she reviewed my lesson plans—she enquired where I learned differentiated instruction, so I told her about the institute - she expressed that she was glad to know that I was able to use what I learned in my teaching.

Overall, from the teacher participants' self-reports, there was a change in the teaching practices of these 20 teachers because of their participation in the institute. The program achieved its goal to help the Mississippi Delta teachers to improve the quality of teaching reading as seen from the paired $t$-test analysis of the pre- and post- test as well as their comments regarding the Institute and its benefits. The institute provided over 32 award winning books offering a diversity of reading experiences across various reading levels to participating teachers. One way to make sure that the group had read these books was through the Read Aloud morning session. Another was through the Reading Assessment. At the Reading Assessment session, the instructor asked the participants to measure the reading level of books provided by the Institute using Fry's Graph Readability Formula (Fry, 1977). To do so, each teacher participant identified and selected 100 word long segments of text from three different portions of each book provided by the institute. These selections had to come from the beginning, middle, and end sections of the books. This ensured that the participants would read each book during the institute.

The management of the program was effective. As one of the participants put it, "The institute was efficiently managed, and that the institute was exactly what they needed to stay abreast of the changes in the education field." The everyday Read Aloud session, the Delta Cultural Field Trip, the process of developing Thematic Units, the presenters' expertise in teaching new strategies to enhance reading, and the increased knowledge and skills in preparing rigorous lesson plans that provided deep learning experiences reflected the successful implementation of the institute's program.

\section{Summary and Conclusions}

In consideration of the preceding description of the institute's program, and the qualitative and quantitative assessment of its efficacy as a means of supporting reading teachers of the Mississippi Delta by providing them with knowledge, skills, and tools to promote the reading experiences of their students, we were able to answer the following questions in a positive manner.

\section{Did the Institute Successfully Equip Teachers to Teach Reading and Language Art to Students in Grades 6-12?}

Over the course of the institute, the teachers took part in 22 sessions designed to improve their teaching practice related to the teaching of reading, and meet the state standards. Feedback from the participants, especially through the focus group discussions, indicated that the institute offered a wide range of beneficial experiences that would facilitate their teaching practice in the classroom. A quantitative assessment of participants' content knowledge, skills, and the thorough understanding of the state standards showed significant changes in pre- and post- test evaluations $(t=20.314, d f=19, p \leq 0.001)$. 
At the first follow-up session (October, 2015), the participants were eager to discuss the changes they made to their classrooms and teaching since the beginning of the school year. They indicated that a number of changes they made to their methods of teaching and how they incorporated many of the teaching strategies learned during the institute. The participants suggested that participating in the institute brought the methods and strategies learned in their teacher education programs to life. Specifically, they talked about Read Aloud, infusing technology, differentiated instruction, infusing rigor in lesson planning, and the various enrichment activities they learned in this institute. The participants expressed their appreciation for the presenters, who they believed were well prepared and knowledgeable, and took the time to explain and modeled the strategies they presented. This allowed them to see which method or strategy they were using correctly, or best practices they knew, but were not using. The institute brought these "into the real world." According to one participant, "There is nothing like the hands-on experiences we received at this Institute."

The novice teachers in the institute expressed that they were more comfortable in the classroom and were now more flexible in their approach to teaching. They now understand it is okay to have a "noisy classroom" if the students are learning.

\section{Did the Institute Enhance Participants' Knowledge and Skills Required to Increase Student Achievement in Reading?}

Based on the participants' responses, the institute affected their practice to teach. All the participants expressed growing confidence in their ability to teach between the first and second follow-up sessions. This, in turn, led to the expectation of an overall growth and achievement of their students, especially those who were not performing as expected at the beginning of the school year. They noticed an increase in their students' engagement and ownership of their learning. Furthermore, as result of reading more, their students' writing improved. These changes made one student ask why his teachers did not use the same methods previously. Our teachers need or should constantly update or modify their teaching skills to meet the new needs of their students.

\section{What Changes Could We Make to Improve the Institute?}

Overall, the well-planned and executed program met all stated objectives. However, the participants did take the exceptions to three presentations made during the Institute. This is not to say that the participants did not learn from these presenters, but that there is room for improvement. What the administration needs to do is to be more specific about the participants' needs when communicating with the presenters. Providing additional guidance to presenters in these three areas would enhance the quality of their instructional presentation.

\section{Recommendations}

Obviously, the institute provided much needed resource for local teachers in the Mississippi Delta. As indicated by the participants, the institute provided them the opportunity to learn new skills, and hone other skills for effective teaching. The program's focus on the state standards meets the demands of the Department of Education in the State of Mississippi by helping the participants' use of current standards to guide their teaching practice.

Participants found modeling and hands-on activities to be beneficial. Books, other quality instructional materials, and teaching aids enabled the transfer of other skills learned in the institute into their everyday teaching practice. The practicality of the institute program gave teachers tools they could use to effectively deliver reading instruction at low cost. 
We want to point out that this is an incentive PD program. We have no way of knowing if the results will be different without stipends, Continuing Education Units, and provision of instructional materials.

As we finished this program evaluation report, we received an email from one of our teacher participants with an attachment showing the signed list of teachers who observed her teaching after she attended the Institute. She told us, because of attending the institute she had become a strong and confident reading teacher. Another piece of evidence demonstrating the success of the institute was the acceptance of one of the Thematic Units developed through the institute for presentation at the Mississippi Reading Association annual conference. We are certain that our experiences of offering this Summer Reading Institute could shed some light on PD of teachers in a rural area with low student academic performance. We want to conclude with a statement from one of the participants:

The institute was very helpful from the presentations on strategies needed to be successful as a reading teacher, to learning how to integrate technology in our teaching, to learning about the culture in which we teach, and to planning and collaborating with our colleagues on thematic units.

\section{References}

Common Core State Standards Initiative. (2011). Retrieved March 20, 2016, from http://www.corestandards.org/assets/CCSSI_ ELA\%20Standards.pdf

Fry, E. (1977). Elementary reading instruction. Burr Ridge: McGraw-Hill.

Gordon, R., Kane, T. J., \& Staiger, D. O. (2006). Identifying effective teachers using performance on the job. Washington, D.C.: Brookings Institution.

Henry, G., Purell, K., Bastian, K., Fortner, C. K., Thompson, C. L., Campbell, S. L., \& Patterson, K. M. (2014). The effects of teacher entry portals on student achievement. Journal of Teacher Education, 65(1), 7-23. doi: 10.1177/0022487113503871

Janssen, S., Kreijins, K., Bastiaens, T., Stijnen, S., \& Vermeulen, M. (2012). Teachers' professional development: An analysis of the use of professional development plans in a Dutch school. Professional Development in Education, $38(3)$, 453-469.

Kimberelis, G., \& Dimitriadis, G. (2005). Focus groups: Strategic articulations of pedagogy, politics, and inquiry. In N. Denzin \& Y. Lincoln (Eds.), The handbook of qualitative research (3rd ed., pp. 887-907). Thousand Oaks, C.A.: Sage.

Madriz, E. (2000). Focus groups in feminist research. In N. Denzin \& Y. Lincoln (Eds.), The handbook of qualitative research (2nd ed., pp. 835-850). Thousand Oaks, C.A.: Sage.

Podhajski, B., Mather, N., Mathan, J., \& Sammons, J. (2009). Professional development in scientifically based reading instruction: teacher knowledge and reading outcomes. Journal of Learning Disabilities, 42(5), 403-417.

Skourdoumbis, A. (2014). Teacher effectiveness: Making the difference to student achievement? British Journal of Educational Studies, 62(2), 111-126. doi: 10.1080/00071005.2014.930413

Skourdoumbis, A., \& Gale, T. (2013). Classroom teacher effectiveness research: A conceptual critique. British Educational Research Journal, 39(5), 892-906. doi: 10.1002/berj.3008

The Mississippi PARCC Assessment. (2015). Retrieved November 7, 2015, from http://reports.mde.k12.ms.us/pdf/a/2015/ Assessment $\% 20$ Brief-PARCC-02NOV015.pdf

The Mississippi PARCC Assessment. (2015). Retrieved February 10, 2016, from http://parcconline.org/assessments/score-results U.S. Census of Bureau. (2016). Retrieved August 10, 2016, from https://www.census.gov/

Wang, Y. (2013). Common core state standards: The new focus of the MVSU NCLB 2012 Summer Reading Institute. Delta Journal of Education, 3(1), 13-23. Retrieved August 15, 2016, from http://www.deltastate.edu/pages/4842.asp 